\title{
Barriers to discharge in an acute care medical teaching unit: a qualitative analysis of health providers' perceptions
}

This article was published in the following Dove Press journal:

Journal of Multidisciplinary Healthcare

12 February 2015

Number of times this article has been viewed

\section{Barbara Okoniewska' \\ Maria Jose Santana' \\ Horacio Groshaus ${ }^{2}$ \\ Svetlana Stajkovic ${ }^{3}$ \\ Jennifer Cowles ${ }^{4}$ \\ David Chakrovorty ${ }^{5}$ \\ William A Ghali'}

'Department of Community Health Sciences, W2IC Research and Innovation Centre, Institute of Public Health, ${ }^{2}$ Department of Internal Medicine, University of Calgary, ${ }^{3}$ Community Based Practice, ${ }^{4}$ Foothills Medical Centre, ${ }^{5}$ Department of Quality and Healthcare Improvement, Alberta Health Services, Calgary, $A B$, Canada
Correspondence: Maria Jose Santana W2IC Research and Innovation Centre, University of Calgary, GD-0I, TRW Building, 3280 Hospital Drive, Calgary, $\mathrm{AB}$, Canada T2N $4 \mathrm{Z6}$

Tel +l 4032109257

$\mathrm{Fax}+\mathrm{I} 4032109850$

Email mjsantan@ucalgary.ca
Background: The complex process of discharging patients from acute care to community care requires a multifaceted interaction between all health care providers and patients. Poor communication in a patient's discharge can result in post hospital adverse events, readmission, and mortality. Because of the gravity of these problems, discharge planning has been emphasized as a potential solution. The purpose of this paper is to identify communication barriers to effective discharge planning in an acute care unit of a tertiary care center and to suggest solutions to these barriers.

Methods: Health care providers provided comments to a single open-ended question: "What are the communication barriers between the different health care providers that limit an effective discharge of patients from Unit 36?" We conducted qualitative thematic analysis by identifying themes related to communication barriers affecting a successful discharge process.

Results: Three broad themes related to barriers to the discharge process were identified: communication, lack of role clarity and lack of resources. We also identified two themes for opportunities for improvement, ie, structure and function of the medical team and need for leadership.

Conclusion: While it was evident that poor communication was an overarching barrier identified by health care providers, other themes emerged. In an effort to increase inter-team communication, "bullet rounds", a condensed form of discharge rounds, were introduced to the medical teaching unit and occurred on a daily basis between the multidisciplinary team. To help facilitate provider-patient communication, electronic transfer of care summaries were suggested as a potential solution. To help role clarity, a discharge coordinator and/or liaison was suggested. Communication can be enhanced through use of electronic discharge summaries, bullet rounds, and implementation of a discharge coordinator(s). The findings from this study can be used to aid future researchers in devising appropriate discharging strategies that are focused around the patient and inter-health care provider communication.

Keywords: communication, discharge planning, continuum of care, acute care setting, barriers

\section{Introduction}

The complex process of discharging patients from acute care to community care requires a multifaceted interaction between all health care providers and patients. Communication between parties is the key to a successful discharge, as this process represents one of the most vulnerable periods in health care delivery. Poor communication in a patient's discharge can result in post hospital adverse events, readmission, and mortality. These post hospital adverse events include medication-related problems that require visits to the emergency department or readmission, such as antibiotic-associated diarrhea, or therapeutic errors, such as prescribing medications that are known to 
interact with or be contraindicated in specific conditions; ${ }^{1}$ for example, combined prescription of angiotensin-converting enzyme inhibitors and nonsteroidal anti-inflammatory drugs, leading to renal failure. ${ }^{1}$

The rate of adverse events for in-hospital patients ranges from $2.5 \%$ to $7.5 \%,{ }^{2-4}$ although the recent literature suggests that the actual rate may be higher than previously anticipated. ${ }^{5}$ Two recent North American studies found an incidence of post-discharge adverse events ranging from $19 \%$ to $23 \%$, with adverse events accounting for $66 \%-72 \%$ of these. ${ }^{4}$ To address this issue, numerous government institutions have developed patient safety organizations aimed at decreasing the incidence of adverse events through increased patient safety. ${ }^{6}$ In 1999, it was estimated that the total cost of preventable adverse events in the USA was between $\$ 17$ billion and \$29 billion annually. ${ }^{7}$ Likewise, the Canadian Patient Safety Institute estimated that the overall economic burden for adverse events in Canada was $\$ 1.1$ billion, of which approximately $\$ 400$ million were due to preventable adverse events. ${ }^{4,8}$ This estimate does not include costs of care after discharge or societal costs of illness. ${ }^{8}$ Furthermore, more than one half of preventable adverse events occurring soon after discharge can be traced back to poor communication during the discharge process. ${ }^{9}$ Other studies have found that medical errors are often the result of communication breakdowns between hospital staff, patients, and primary care physicians (PCPs). ${ }^{10}$ Thus, it is imperative that efforts are made to reduce the rate of adverse events, and improving patient safety using discharge planning has been emphasized as a potential solution.

Discharge planning is the development of an individualized discharge plan for the patient prior to leaving the hospital, with the aim to reduce medical costs, improve patient outcomes, and reduce length of stay and unplanned readmissions. ${ }^{11}$ The process strives to ensure that patients are discharged at an appropriate time and that sufficient support is accessible in the community when required. ${ }^{11,12}$ Many government institutions worldwide have adopted discharge planning and integrated it into national practices. In the USA, discharge planning is mandatory for all hospitals participating in Medicare and Medicaid programs. ${ }^{11,13}$ The UK initiated a discharge planning system that begins on the day of admission, ${ }^{14-16}$ and in Australia the Victorian government identified four important components to discharge planning and implemented them across all public Victorian hospitals. ${ }^{17}$

In 2011, a Cochrane review identified 21 randomized clinical trials assessing the efficacy of discharge planning. This review showed that discharge planning can reduce the length of hospital stay for all patients and readmission rates for elderly patients. ${ }^{11}$ Despite the growing body of evidence and international emphasis on discharge planning, many institutions experience barriers to effective discharge planning. Furthermore, ineffective planning can result in delayed discharges, causing a backlog in the hospital system. For example, one study showed that patient transfers from the intensive care unit to acute care units was unsuccessful $33 \%$ of the time due to lack of acute care beds and this was a result of discharge delays in the acute care unit. ${ }^{18}$ Consequently, many acute care units may prematurely discharge patients to relieve the pressure of bed unavailability. ${ }^{19}$ These delays in effective discharges are often due to a breakdown of communication, including health care provider's perception of patient health literacy, lack of standardized discharge protocols, and lack of post-discharge support. ${ }^{10,19,20}$

While there are many studies in the literature that highlight the importance of discharge planning, few studies have approached health care professionals and identified perceived barriers. The purpose of this paper is to identify barriers to effective discharge planning as identified by health care workers in an acute care medical teaching unit at a tertiary care center, and to suggest solutions to these barriers.

\section{Materials and methods Study and setting}

The present study is a qualitative content analysis of the perceptions of health care providers about communication barriers to effective discharge planning. The study was conducted over the course of a 1-month rotation at the Ward of the 21 st century (W21C), Unit 36, a medical teaching unit affiliated with the University of Calgary, Alberta, Canada. The focus of W21C is to conduct interdisciplinary research on health system safety and quality (see http://www.w21c. org). Nurses, allied health providers, internal medicine residents, and attending medical staff working in the unit were candidates for this study. The study was considered a quality improvement activity in which personal identifiable data were not revealed and participant anonymity was maintained.

\section{Data collection}

Health care provider perceptions about the communication barriers limiting effective discharge planning were collected by a researcher during health care provider shifts. Health care providers were asked to provide comments by answering a single open-ended question: "What are the communication barriers between the different health care providers that limit an effective discharge of patients from Unit 36?'. Participants were given cue-cards with the question and were asked 
to provide their written answers. There was no limitation as to how long their answers could be. Answers were collected by researchers at the end of the shift. Answers were then cataloged based on the action identified, the services impacted, and the impact on the discharge process. Data were further categorized based on comments provided by health care providers (physician, allied health staff, residents, nursing staff), and specifically which process was being identified.

\section{Data analysis}

We conducted qualitative thematic analysis by identifying themes related to barriers affecting a successful discharge process. Answers to free text questions were grouped thematically using thematic analysis. ${ }^{21}$

\section{Results}

We received written comments from eleven allied health providers, 26 nurses, 25 internal medicine residents, and seven attending medical staff. We identified three broad themes related to barriers in the discharge process (Table 1) and two themes suggesting opportunities for improvement (Table 2).

\section{Barriers to an effective discharge process Communication}

Communication was identified by all members of the team as an important factor influencing an effective discharge process. In particular, health care providers described the communication gap between team members:

Teams don't always alert allied health services of our discharge plans. Patient may be ready medically for discharge, but not from a rehabilitation point of view [...]

Team doesn't communicate the need for patient education, eg, DM nurse educator, pharmacy teaching, anticoagulation clinic.

\section{Lack of role clarity}

Another important barrier identified was the lack of role clarity. Participants suggested that it was important to have all the relevant parties involved at the time of discharge planning as well as clarifying their tasks:

[...] unclear who ultimately has the responsibility to review the discharge plans, medications, follow-up appointments, eg, RN, person who wrote the discharge summary, senior resident.

\section{Lack of resources}

Lack of resources was highlighted as a key issue with regard to achieving an effective discharge plan. Most of the participants considered not only the lack of resources allocated to acute care but also to community care as limiting adequate follow-up care:

In many ways I think the problem is more outside the hospital than inside - not enough GPs, finding resources.

\section{Opportunities for improvement in discharge planning}

Participants' comments about the barriers identified with regard to an effective hospital discharge plan were accompanied by opportunities to improve the process. These opportunities were grouped into two themes, as follows:

- Structure and function of the medical team, whereby additional documentation was suggested to improve the structure, including protocols to ensure effective and timely transition of care. The team highlighted the need to provide patients with information about follow-up appointments and educational materials. The team suggested reviewing the effectiveness of discharge rounds, emphasizing the need for a tool that will help them to communicate. A potential tool described by some of the team members was "bullet rounds", a condensed form of discharge rounds involving various members of the multidisciplinary team and occurring on a daily basis.

- Need for leadership

The team recognized that the lack of a consistent charge nurse often left the rotating nurses "out of the loop" regarding discharge planning. A solution to miscommunication amongst team members and to the lack of role clarity could be to create a new team care coordinator position. A team care coordinator will be vital because they can act as a central knowledge repository and can liaise with the rest of the team members, thereby coordinating the discharge process in an effective fashion.

\section{Discussion}

We have conducted a qualitative study exploring health care provider perceptions with regard to effective discharge from an acute care medical teaching unit. While our question was directed toward communication, our results identified three key themes, ie, communication gaps between team members, lack of role clarity within the discharge process, and a lack of resources. We were also able to identify opportunities 
Table I Key themes perceived as barriers to discharge by health care providers

\begin{tabular}{ll}
\hline Key theme & Subthemes \\
\hline Communication gaps & $\begin{array}{l}\text { Between health care } \\
\text { providers and patients }\end{array}$
\end{tabular}
Supporting quotes

providers and patients

"Patient doesn't tell us they have concerns or want help/home care etc until the last minute" "MD's often forget if patients are from out of town and have to arrange rides. Need 2-3 days' notice of discharge for families to rearrange work/family"

"Patient doesn't know what their admission medications are so it is hard to consolidate them on discharge"

"Inconclusive information about further follow up with other services that were consulted during admission"

Amongst medical residents

"Poor communication within the medical team (eg, patient still on IV meds, SC meds (insulin SS), home meds not restarted) - all delay discharge"

"Doctors should put in discharge order have summary and prescription done evening before discharge. If stable in the morning, then discharge at 0900 hours"

"Weekend discharges are tricky to arrange, especially if person left to discharge patient does not know him/her. Cannot book appointments usually"

Between medical residents "Discrepancy between the information given to patient/nurse and final decision after rounds" and nurses "Discharge plan not clearly documented in chart - this is the main way of communication between MD and RN, then RN caught off guard with discharge orders because it was not clearly communicated"

Between medical residents “Teams don't always alert allied health services of our discharge plans. Patient may be ready medically for discharge, but not from a rehabilitation point of view. We need communication with these services probably more than once a week at discharge rounds" "Does not seem that teams review our [allied health] documentation. It is frustrating when I am reconsulted on a patient I am already involved with and working through a treatment plan"

Between allied health and nurses

"TS are notorious for not charting or charting in unknown location ... we as floor staff need to know what is going on - are they waitlisted? Are they eligible? It is usually us that attempt to answer the patient's questions. As well, knowing this information helps us get prep work ready in advance"

Amongst nurses

"Communication between charge nurse and unit clerks to organize paper work, fax med list and discharge summary, etc"

Between acute care physicians and community care physicians

Amongst the health care providers/multidisciplinary team

"I think the largest issue is that our patients are very complicated and dictation's can take weeks post discharge. This can result in delay of important medical information to the primary physician. Although we write written copies, they often are not brought to follow up appointments. I think we need to hire more transcriptions"

"All tests that are to be done as outpatient should be written on discharge planning sheet with dates listed. Same for follow up appointments. Ensure consultation service who requests follow up leaves MD name and office number on chart"

"What is communicated/discussed/decided in discharge rounds is very rarely passed on to nursing (floor) staff. We need to be involved and in the loop. As often it is us that have parts to play as does PT/OT etc. We all need to know what goes on and what we can do to get patients ready to go"

"Discharges don't always have 24 hours notice - cause communication breakdown when everyone is rushing"

Lack of role clarity

"Unclear who ultimately has the responsibility to review the discharge plans, medications, follow up appointments (ie, RN, person who wrote the discharge summary, senior resident)"

"Unclear roles of professionals at times, overlook the whole picture, lack of case management in a specified role"

"Lack of clear understanding of rehab role"

"Biggest issues in delayed discharges is lack of resources (eg, rehabilitation beds, nursing home beds, etc ...). We usually plan early, whole team involved and there is nowhere for the patient to go!"

Abbreviations: MD, Doctor of Medicine; SC, subcutaneous; PT, physiotherapist; RN, registered nurse; OT, occupational therapist; SW, social worker.

for improvement. The main outcome of the study was implementation of bullet rounds and clarification of the role of the discharge coordinator in the medical teaching unit.

Poor communication between health care providers was identified as a major overarching issue. Physicians, residents, medical clerks, nurses, allied health staff (eg, physiotherapists, occupational therapists, social workers, transitional services nurse, dietitians, pharmacists), mental health unit clerks, different educators (eg, diabetes, anticoagulation) are all involved in the discharge process. There are simply too many links in 
Table 2 Identified opportunities for improvement

\begin{tabular}{|c|c|}
\hline Opportunities for improvement & Supporting quotes \\
\hline \multicolumn{2}{|l|}{ Structure and function of the medical team } \\
\hline \multirow{4}{*}{$\begin{array}{l}\text { Discharge documents including follow-up } \\
\text { and patient education }\end{array}$} & “... I think all patients should receive copies of the investigations done during admission \\
\hline & and discharge summary to facilitate out-patient follow up (family doctors, etc ...)" \\
\hline & "Patient should go home with a copy of the discharge summary" \\
\hline & "Discharges as rushed or later in the day" \\
\hline \multirow[t]{5}{*}{ Effectiveness of the discharge rounds } & "Current design of weekly multidisciplinary rounds is not helpful in discharge planning ... it would \\
\hline & be better to have quick bullet rounds each morning with everyone on the team (MDs, nursing, \\
\hline & rehab, SW) where we quickly run through the day's plan for each patients (have done this in other \\
\hline & academic hospitals I have worked at and it works very well)... can get through I 5 patients in under \\
\hline & I5 minutes ... this also helps to get to know all members of your healthcare team" \\
\hline \multirow[t]{4}{*}{ Communication between health care providers } & "Clear documentation of intent to discharge should be in chart as this is one place where \\
\hline & all team members have access" \\
\hline & “I didn't find much problems in discharge planning as long as I let nursing know what the plans \\
\hline & are and the sooner I communicate with nursing the better" \\
\hline Need for leadership & "a team care coordinator is vital ..." \\
\hline
\end{tabular}

Abbreviations: MD, Doctor of Medicine; SW, social worker.

this chain that can be broken. Since the Institute of Medicine's groundbreaking publication entitled "To Err Is Human: Building a Safer Health System", and its follow-up publication entitled "Crossing the Quality Chasm: A New Health System for the 21st Century", poor communication has been identified as a major contributor to medical errors. ${ }^{22,23}$ More recent literature shows that poor communication between medical teams accounts for up to $70 \%$ of medical errors. ${ }^{24}$ In an effort to increase inter-team communication, the idea of bullet rounds, a condensed form of discharge rounds, was introduced to the medical teaching unit. Studies have shown that short discharge rounds conducted in a multidisciplinary environment can increase communication between parties, shorten a patient's length of stay, and ensure continuity of care. ${ }^{25-27}$ Bullet rounds occur on a daily basis between the senior resident and/or the attending staff physician, the charge nurse, the discharging coordinator(s), and the allied health staff. Six key points are addressed in this meeting, including an estimate of the expected length of stay for patients; which patients are to be discharged immediately and what are the barriers to their discharge; where the patient is being discharged to; what is the patient's medical plan for the day; what needs to be addressed in the medical plan before considering discharge; and are there any outpatient appointments or follow-ups that should be set before discharge? These rounds present the opportunity for all health care providers to report their progress or barriers with a patient and to provide a quick snapshot of the patient's discharge status. More lengthy discussions take place outside of bullet rounds in a team or family meeting. A follow-up study will be conducted to evaluate the effectiveness of the bullet rounds.

Communication between health care providers and patients is vital for patient safety and the quality of care received. Studies have shown that positive patient experiences have been linked to patient health status, ${ }^{28}$ while negative patient experiences have been linked to adverse health outcomes. ${ }^{29}$ Miscommunication in patient instructions and unclear follow-up appointments can lead to post hospital adverse events, patient dissatisfaction, confusion, and delays in discharge. ${ }^{4,30-33}$ Participants indicated that patients would benefit from receiving a discharge summary that included clear follow-up instructions and appointments, and could also serve as a tool to assist in medical reconciliation. Since this study was conducted, the University of Calgary in partnership with Alberta Health Services (the provincial health authority) and iterative consultation with multiple clinical stakeholders as well as patients and family developed an electronic transfer of care communication tool that generates transfer of care summaries. The tool was built on the already functioning electronic platform (Sunrise Clinical Manager, Eclipsys Corporation, Boca Raton, FL, USA) that physicians use to manage inpatient orders and to access patient medical records, diagnostic imaging, and laboratory results. Currently, a randomized clinical trial is underway assessing the efficacy of the transfer of care summary in regards to adverse events, readmission, and mortality, with secondary endpoints of timeliness and patient and physician satisfaction. ${ }^{34}$ It is thought that an electronic transfer of care summary can be at least a partial solution to poor health care provider-patient interaction. ${ }^{34}$ When leaving the hospital, patients receive a full copy of their transfer of care summary which contains information about their follow-up appointments. The summary clarifies the status of the appointments, indicating if the appointment has already been scheduled, in which case the date and time of the appointment is included (eg, for follow-up magnetic resonance imaging), whether the clinic 
will be contacting the patient to schedule an appointment (eg, internal medicine clinic), or whether the patient is required to arrange the appoint on their own (eg, with family doctor). In addition, these summaries are uploaded onto the provincial health network (NetCare) and made available to family physicians within a week of discharge. The transfer of care summaries also include follow-up instructions for the general practitioner, with instructions regarding what laboratory tests need to be conducted.

A lack of role clarity in the discharge process was identified as one of the key issues. It is therefore imperative to implement a discharge coordinator in order to improve the discharge planning process. Studies have shown that employing a discharge coordinator leads to improved discharge planning and a reduction in problems that patients face after discharge. ${ }^{14,35}$ Currently, the medical teaching unit is equipped with both a discharge coordinator and a discharge liaison to help facilitate the process, to ensure all issues have been addressed, and to ensure that the patient is aware of follow-up plans.

A lack of resources was also perceived as a key issue in the discharge process, particularly the lack of patient beds in an acute care center and resources for patients following discharge. A recent Cochrane review found that proper discharge planning led to a small reduction in length of stay and readmission rates in older patients with a medical condition. ${ }^{11}$ It can be extrapolated from this evidence that a decrease in the length of stay could result in better bed availability and allocation.

We know that the transition from an acute care center to the community constitutes one of the most vulnerable periods for patients, with $23 \%$ of patients experiencing post hospital adverse events, $11 \%$ of which are either ameliorable or preventable. ${ }^{1}$ Confusion often arises with regard to discharge instructions, medication regimens, and what community services are available to the patient. In addition, while many community services are available to patients after discharge, based on our results, there appears to be a gap in communication between health care providers, patients, and community services, creating a larger impression of resource scarcity. This gap can be bridged by better communication with the PCP, ${ }^{36}$ post discharge support for the patient, ${ }^{37}$ as well as translation of knowledge regarding community resources to the PCP. Enhanced communication with the PCP can be accomplished by timely electronic transfer of care summaries that include information regarding the discharge diagnosis, medications, pending test results, results of procedures, follow-up arrangements, and suggested future steps. ${ }^{36,38-40}$ Post discharge support in the form of frequent telephone follow-up has been shown to reduce the risk of readmission. ${ }^{37,41}$ Finally, since most patients require followup visits with their PCP, it makes intuitive sense that the PCP would be knowledgeable with regard to the community resources available and suitable for the patient. We would suggest frequent knowledge translation sessions between community resources and the PCP to help provide support to the PCP in such a task. With the help of these three interventions, we would predict that the impression of resource scarcity would diminish, although more research focusing on these three interventions simultaneously would be required before a definitive opinion can be expressed.

\section{Conclusion}

The present qualitative study explored the perceptions of health care providers with regard to barriers to discharge in an acute care medical teaching unit. Our findings indicate that the key issues are centered on communication, role clarity, and lack of resources. Communication can be enhanced by use of electronic discharge summaries and bullet rounds, while appointment of a discharge coordinator can help facilitate role clarity. The findings of this study can be used to aid future work in devising appropriate discharge strategies that are focused around the patient and communication between health care providers.

\section{Disclosure}

The authors report no conflicts of interest in this work.

\section{References}

1. Forster AJ, Clark HD, Menard A, et al. Adverse events among medical patients after discharge from hospital. CMAJ. 2004;170(3):345-349.

2. Thomas EJ, Studdert DM, Burstin HR, et al. Incidence and types of adverse events and negligent care in Utah and Colorado. Med Care. 2000;38(3):261-271.

3. Leape LL, Brennan TA, Laird N, et al. The nature of adverse events in hospitalized patients: results of the Harvard Medical Practice Study II. N Engl J Med. 1991;324(6):377-384.

4. Baker GR, Norton PG, Flintoft V, et al. The Canadian Adverse Events Study: the incidence of adverse events among hospital patients in Canada. CMAJ. 2004;170(11):1678-1686.

5. Classen DC, Resar R, Griffin F, et al. "Global trigger tool" shows that adverse events in hospitals may be ten times greater than previously measured. Health Aff (Millwood). 2011;30(4):581-589.

6. World Health Organization. WHO draft guidelines for adverse event reporting and learning system. Available from: http://www.who. int/patientsafety/events/05/Reporting_Guidelines.pdf. Accessed September 27, 2014.

7. Thomas EJ, Studdert DM, Newhouse JP, et al. Costs of medical injuries in Utah and Colorado. Inquiry. 1999;36(3):255-264.

8. Mittmann N, Koo M, Daneman N, et al. The economic burden of patient safety targets in acute care: a systematic review. Drug Healthc Patient Saf. 2012;4:141-165. 
9. Roy CL, Poon EG, Karson AS, et al. Patient safety concerns arising from test results that return after hospital discharge. Am Coll Physicians. 2005;143(2):121-129.

10. Mcleod LA. Patient transitions from inpatient to outpatient: Where are the risks? Can we address them? Am Soc Healthc Risk Manag. 2013;32(3):13-19.

11. Shepperd S, McClaran J, Co P, et al. Discharge planning from hospital to home. Cochrane Database Syst Rev. 2010;1:CD000313.

12. Robinson S, Howie-Esquivel J, Vlahov D. Readmission risk factors after hospital discharge among the elderly. Popul Health Manag. 2012;15(6): 338-351.

13. Yam CH, Wong EL, Cheung AW, Chan FW, Wong FY, Yeoh E. Framework and components for effective discharge planning system: a Delphi methodology. BMC Health Serv Res. 2012;12(1):396.

14. Summerton H. Discharge planning: establishing an effective coordination team. Br J Nurs. 1996;7(20):1263-1267.

15. Katikireddi SV, Cloud GC. Planning a patient's discharge from hospital BMJ. 2008;337:a2694-a2694.

16. The Health Boards Executive. Admissions and Discharge Guidelines: Health Strategy Implementation Project 2003. Available from: http://www.dohc.ie/issues/health_strategy/action84.pdf?direct=1. Accessed July 2, 2013.

17. Victorian Government Health Information. Background Paper: A Framework for Effective Discharge. Melbourne, Australia: Department of Human Services; 1998.

18. Lin F, Chaboyer W, Wallis M, Miller A. Factors contributing to the process of intensive care patient discharge: an ethnographic study informed by activity theory. Int J Nurs Stud. 2013;50(8): 1054-1066.

19. Wong EL, Yam CH, Cheung AW, et al. Barriers to effective discharge planning: a qualitative study investigating the perspectives of frontline healthcare professionals. BMC Health Serv Res. 2011;11(1):242.

20. Marcantonio ER, McKean S, Goldfinger M, Kleefield S, Yurkofsky M, Brennan TA. Factors associated with unplanned hospital readmission among patients 65 years of age and older in a Medicare managed care plan. Am J Med. 1999;107(1):13-17.

21. Guest G, MacQueen KM, Namey EE. Applied Thematic Analysis. Thousand Oaks, CA, USA: Sage Publications; 2012.

22. Institute of Medicine. Kohn LT, Corrigan JM, Donaldson MS, editors To Err Is Human: Building a Safer Health System. Washington, DC, USA: National Academies Press; 1999.

23. Institute of Medicine. Crossing the Quality Chasm: A New Health System for the 21st Century - Institute of Medicine. Washington, DC, USA: The National Academies Press; 2001.

24. Studdert D, Brennan T, Thomas E. What have we learned from the Harvard Medical Practice Study? In: Rosenthal M, Sutcliffe K, editors. Medical Error: What Do We Know? What Do We Do? London, UK: BMJ Group; 2002.

25. Sen A, Xiao Y, Lee S-A, et al. Daily multidisciplinary discharge rounds in a trauma center: a little time, well spent. J Trauma. 2009;66(3):880-887.
26. Haan JM, Dutton RP, Willis M, Leone S, Kramer ME, Scalea TM Discharge rounds in the 80-hour workweek: importance of the trauma nurse practitioner. J Trauma. 2007;63(2):339-343.

27. Dutton RP, Cooper C, Jones A, Leone S, Kramer ME, Scalea TM. Daily multidisciplinary rounds shorten length of stay for trauma patients. J Trauma. 2003;55(5):913-919.

28. Donabedian A. Explorations in Quality Assessment and Monitoring. Vol 1. The Definition of Quality and Approaches to Its Assessment. Ann Arbor, MI, USA: Health Administration Press; 1980.

29. Baker D, Stevens C, Brook R. Patients who leave a public hospital emergency department without being seen by a physician. JAMA 1991;266(8):1085-1090.

30. Forster AJ, Clark HD, Menard A, et al. Adverse events among medical patients after discharge from hospital. CMAJ. 2004;170(3):345-349.

31. Forster AJ, Murff HJ, Peterson JF, Gandhi TK, Bates DW. The incidence and severity of adverse events affecting patients after discharge from the hospital. Ann Intern Med. 2003;138(3):161-174.

32. Forster AJ, Asmis TR, Clark HD, et al. Ottawa hospital patient saftey study: incidence and timing of adverse events in patients admitted to a Canadian teaching hospital. CMAJ. 2004;170(8):1235-1240.

33. Charles C, Gauld M, Chambers L, O’Brien B, Haynes RB, Labelle R. How was your hospital stay? Patients' reports about their care in Canadian hospitals. CMAJ. 1994;150(11):1813-1822.

34. Okoniewska BM, Santana MJ, Holroyd-Leduc J, et al. The Seamless Transfer-of-Care Protocol: a randomized controlled trial assessing the efficacy of an electronic transfer-of-care communication tool. $B M C$ Health Serv Res. 2012;12(1):414.

35. Houghton A, Bowling A, Clarke KD, Hopkins AP, Jones I. Does a dedicated discharge coordinator improve the quality of hospital discharge? Qual Health Care. 1996;5(2):89-96.

36. Kripalani S, Jackson AT, Schnipper JL, Coleman EA. Promoting effective transitions of care at hospital discharge: a review of key issues for hospitalists. J Hosp Med. 2007;2(5):314-323.

37. Phillips CO, Wright SM, Kern DE, Singa RM, Shepperd S, Rubin HR. Comprehensive discharge planning with postdischarge support for older patients with congestive heart failure: a meta-analysis. JAMA. 2004;291(11):1358-1367.

38. Callen JL, Alderton M, McIntosh J. Evaluation of electronic discharge summaries: a comparison of documentation in electronic and handwritten discharge summaries. Int J Med Inform. 2008;77(9):613-620.

39. Branger PJ, van der Wouden JC, Schudel BR, et al. Electronic communication between providers of primary and secondary care. $B M J$. 1992;305(6861):1068-1070.

40. Motamedi SM, Posadas-Calleja J, Straus S, et al. The efficacy of computer-enabled discharge communication interventions: a systematic review. BMJ Qual Saf. 2011;20(5):403-415.

41. Grancelli H, Varini S, Ferrante D, et al. Randomized Trial of Telephone Intervention in Chronic Heart Failure (DIAL): study design and preliminary observations. J Card Fail. 2003;9(3):172-179.
Journal of Multidisciplinary Healthcare

\section{Publish your work in this journal}

The Journal of Multidisciplinary Healthcare is an international, peerreviewed open-access journal that aims to represent and publish research in healthcare areas delivered by practitioners of different disciplines. This includes studies and reviews conducted by multidisciplinary teams as well as research which evaluates the results or conduct of such teams or

\section{Dovepress}

healthcare processes in general. The journal covers a wide range of areas and welcomes submissions from practitioners at all levels, from all over the world. The manuscript management system is completely online and includes a very quick and fair peer-review system. Visit http://www.dovepress.com/testimonials.php to read real quotes from published authors. 